\title{
EMPREGO DO NITENPYRAM COMO LARVICIDAEM MIÍASES CANINAS POR Cochliomyia hominivorax
}

\author{
USE OF NITENPYRAMAS A LARVICIDE IN CANINE MYIASIS CAUSEDBY \\ LARVAE OF Cochliomyia hominivorax
}

\author{
MAUROLUÍS DASILVAMACHADO ${ }^{1}$ \& EGLETE MARIAPACHECO RODRIGUES ${ }^{2}$
}

\begin{abstract}
RESUMO
Miíase é a invasão de tecidos ou cavidades abertas do organismo animal por larvas de dípteros. Nos cães, a miíase de maior gravidade é a causada pela $C o$ chliomyia hominivorax. No Hospital de Clínicas Veterinárias da UFRGS (HCV/UFRGS) tem-se utilizado como medicação larvicida prévia à limpeza das miíases a droga nitenpyram (Capstar $\left.{ }^{\circledR}\right)$, embora tal medicamento seja indicado somente como pulicida para cães e gatos. O objetivo deste estudo foi avaliar a eficácia do nitenpyram como larvicida em miíases por larvas de Cochliomyia hominivorax em cães atendidos no HCV/UFRGS(Porto Alegre - RS). Administrou-se nitenpyram na dosificação indicada pelo fabricante como pulicida (de 1,00 até $3,56 \mathrm{mg} / \mathrm{kg}$ ) a 17 cães com miíase. Nenhuma outra medicação foi prescrita, nem foi efetuado qualquer procedimento de limpeza até o retorno em 24 horas. No retorno, observou-se em 16 animais (94,11\%) que 100\% das larvas encontradas estavam mortas e que o quadro clínico apresentava uma grande melhora, com redução da ferida. Em um cão que havia recebido a dose de $1 \mathrm{mg} / \mathrm{kg}$ foi ainda observada larvas vivas em 24 horas. Não foi observado clinicamente nenhuma reação adversa ao medicamento. $\mathrm{O}$ nitenpyram, na dosagem mínima de $1 \mathrm{mg} / \mathrm{kg}$ em dose única, mostrou-se eficaz como larvicida para larvas de moscas $\mathrm{Co}$ chliomyia hominivorax em $94,11 \%$ dos cães estudados.
\end{abstract}

Descritores: miíases, Cochliomyia hominivorax, cães, nitenpyram.

\begin{abstract}
Myiasis is a pathological condition caused by larvae of dipterous in living tissues. The most harmful myiasis in dogs is caused by the larvae of the fly Cochliomyia hominivorax . At the Hospital de Clínicas Veterinárias [Veterinary Medical Teaching Hospital], da Universidade Federal do Rio Grande do Sul, Porto Alegre-RS (HCV/UFRGS), nitenpyram (Capstar $\left.{ }^{\circledR}\right)$ has been used as larvicide before cleaning the wounds, although such drug is indicated by the company only as pulicide for dogs and cats. The aim of this study was to evaluate the efficacy of nitenpyram against larvae of Cochliomyia hominivorax in dogs with myiasis treated at HCV/UFRGS. Nitenpyram, at the routine dosage indicated as a pulicide ( ranging from 1 to $3,56 \mathrm{mg} / \mathrm{kg}$ ), was administered to $17 \mathrm{dogs}$, without employing other medical, cleaning or combined procedure. All the animals were examinated again within a period of 24 hours, and it was observed that all recovered larvae were dead and the wounds presented a great improvement in 16 cases $(94,11 \%)$. In only one dog that had received the dosage of $1 \mathrm{mg} / \mathrm{kg}$, viable larvae could still be observed. No adverse reaction to the drug was clinically remarked. These results suggest that a single dose of nitenpyram, even at a minimal dosage of $1 \mathrm{mg} / \mathrm{kg}$, should be considered as a very efficacious larvicidal against larvae of Cochliomyia hominivorax .
\end{abstract}

Key words: myiasis, Cochliomyia hominivorax, dogs, nitenpyram. 
Míase é a invasão de tecidos ou cavidades abertas do organismo animal por larvas de dípteros [1]. São consideradas miíases específicas aquelas causadas por moscas cujas larvas são parasitas obrigatórios, pois nutrem-se de tecidos vivos. As mí́ases são divididas em três formas: cutânea (depósito de ovos de moscas em ulcerações de pele), cavitária (depósito de ovos de moscas nas cavidades nasal, oral, anal, auditiva, orbital, etc.) e intestinal ( por ingestão de larvas em bebidas ou alimentos contaminados) [4].

Nos cães, a maioria das míases são causadas pela Dermatobia hominis, que causa uma mí́ase furunculóide primária ("berne") e, pela Cochliomyia hominivorax, causadora de uma míase cutânea ou cavitária ("bicheira"), forma mais freqüente e grave de milíase.

A C. hominivorax realiza as posturas em ferimentos recentes da pele ou cavidades de animais vivos. Em 12 a 24 horas surgem as larvas do primeiro estágio (L1), que evoluem e realizam duas ecdises, transformando-se em L3 em 6 a 7 dias, quando então abandonam espontaneamente o hospedeiro para pupar no solo. Em condições ótimas de temperatura e umidade do ar, o ciclo evolutivo se completa em 21 a 23 dias. As larvas possuem enzimas proteolíticas, responsáveis pela digestão dos tecidos do hospedeiro. As lesões aumentam gradativamente e exalam um odor repulsivo. De acordo com a localização da míiase, poderá ocorrer peritonite, claudicação, cegueira, afecções dentárias, etc. Os animais ficam inquietos, deixam de se alimentar e emagrecem. A morte pode ocorrer por toxemia, hemorragia ou infecções bacterianas secundárias [2].

Para o tratamento das mí́ases cutâneas e cavitárias são indicados tradicionalmente a limpeza do local, tricotomia (se necessária), debridamento dos tecidos necrosados, remoção das larvas, terapia antimicrobiana local e/ou sistêmica e tratamento local com repelentes e larvicidas [3]. Para se efetuar esses procedimentos, freqüentemente é indispensável a tranqüilização ou anestesia geral do animal.

No Hospital de Clínicas Veterinárias da Universidade Federal do Rio Grande do Sul (HCV/UFRGS) tem-se utilizado a droga nitenpyram (Capstar $\left.{ }^{\circledR}\right)^{1}$ como medicação larvicida prévia à limpeza das miíases, muito embora tal medicamento não tenha essa indicação pelo fabricante, nem encontra-se na literatura veterinária relatos de seu uso para essa finalidade.

O nitenpyram é indicado para tratamento de rápida ação nas infestações de pulgas em cães e gatos, e sua ação inicia entre 15 a 30 minutos após a administração oral, matando todas as pulgas que estejam no animal em até seis horas. Permanece ativo nos cães por 24 horas e nos gatos por 48 horas. São apresentados em blister de alumínio contendo seis comprimidos de Capstar ${ }^{\circledR}$ de $11,4 \mathrm{mg}$ ou $57 \mathrm{mg}$. A dose recomendada é de no mínimo $1 \mathrm{mg}$ por quilo corporal, ou, um comprimido de 11,4 mg para gatos, independente do peso, e um comprimido de $11,4 \mathrm{mg}$ para cães até $11,4 \mathrm{~kg}$ e um comprimido de $57 \mathrm{mg}$ para cães acima de $11,4 \mathrm{~kg}$. O nitenpyram é uma droga pertencente ao grupo dos nicotinóides, que agem no sistema nervoso central dos insetos e mamíferos causando bloqueio pós-sináptico irreversível nos receptores nicotinérgicos da acetilcolina. [5].

O objetivo deste estudo foi avaliar a eficácia do nitenpyram como larvicida para larvas de moscas C. hominivorax em milíases cutâneas e cavitárias em cães atendidos no HCV/UFRGS, utilizando-se a mesma dosagem recomendada pelo fabricante como pulicida.

Foram utilizados 17 cães atendidos na clínica de pequenos animais com diagnóstico de miíase cutânea ou cavitária por larvas de $C$. hominivorax. Os animais foram avaliados clinicamente e foi administrado nitenpyram na dosificação indicada pelo fabricante como pulicida em todos animais, ficando as dosagens assim distribuídas: dois cães receberam doses de 1 $\mathrm{mg} / \mathrm{kg}$; seis cães doses entre $1,51-2,00 \mathrm{mg} / \mathrm{kg}$; cinco cães doses entre $2,01-2,50 \mathrm{mg} / \mathrm{kg}$; três cães doses entre $2,51-3,00 \mathrm{mg} / \mathrm{kg}$ e um cão a dose de $3,56 \mathrm{mg} /$ $\mathrm{kg}$. Os animais foram reavaliados em 24 horas para constatação do estado das larvas e da ferida.

Dos 17 animais avaliados, $16(94,11 \%)$ apresentaram, em 24 horas, morte em 100\% das larvas encontradas, observando-se uma grande melhora no quadro clínico, com redução da ferida e, em muitos casos, com diminuição do número e até ausência total de larvas. Em um cão de $57 \mathrm{~kg}$ foi dado somente 


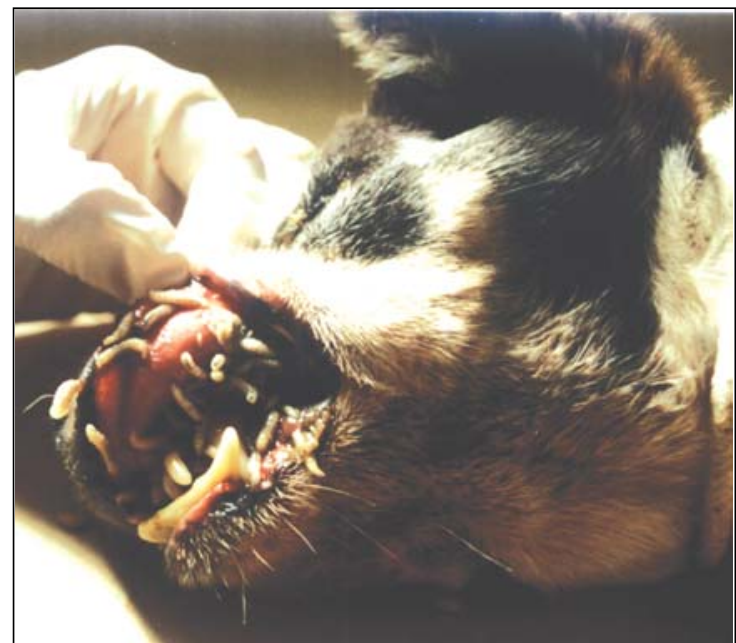

Figura 1a. SRD, macho, 15 anos. Mí́ase cavitária oral. [Foto: M.L.S Machado]

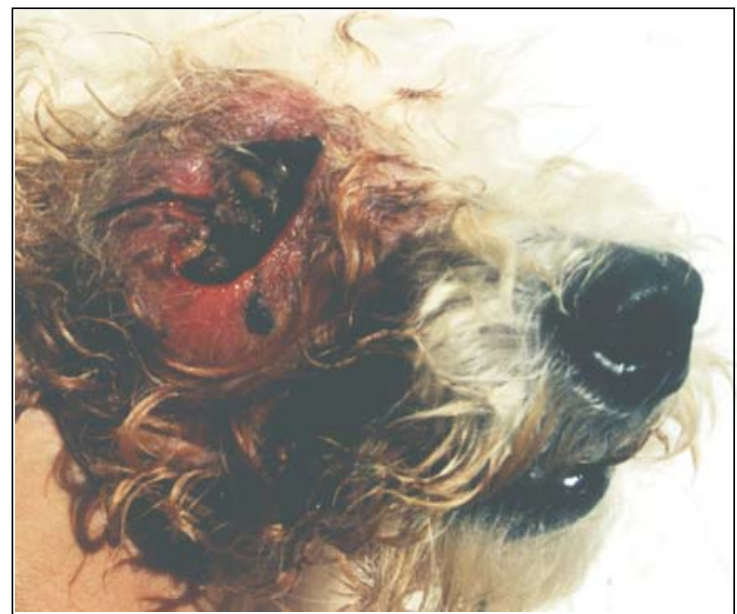

Figura 2a. Poodle, fêmea, 16 anos. Miíase cavitária região orbital direita. [Foto: M.L.S Machado]

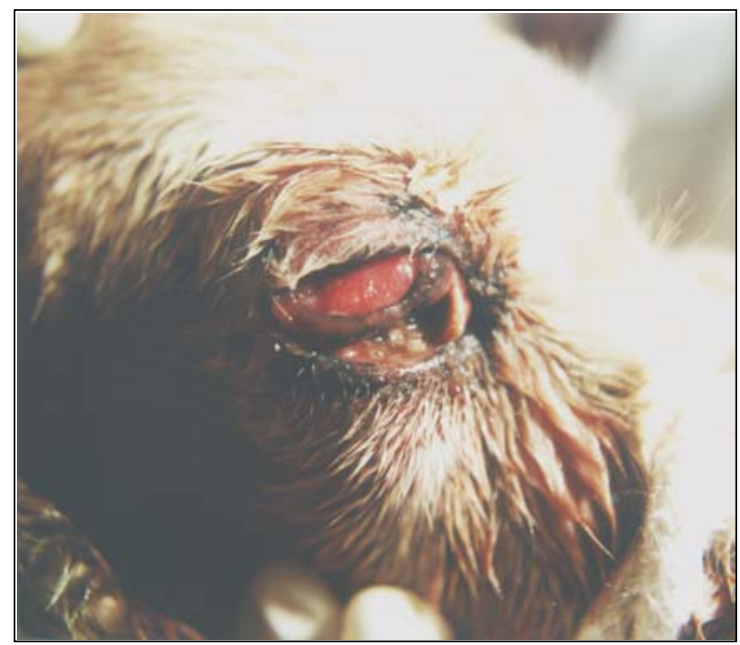

Figura 3a. Cocker, macho, 10 anos. Miíase cavitária região orbital direita. [Foto: M.L.S Machado]

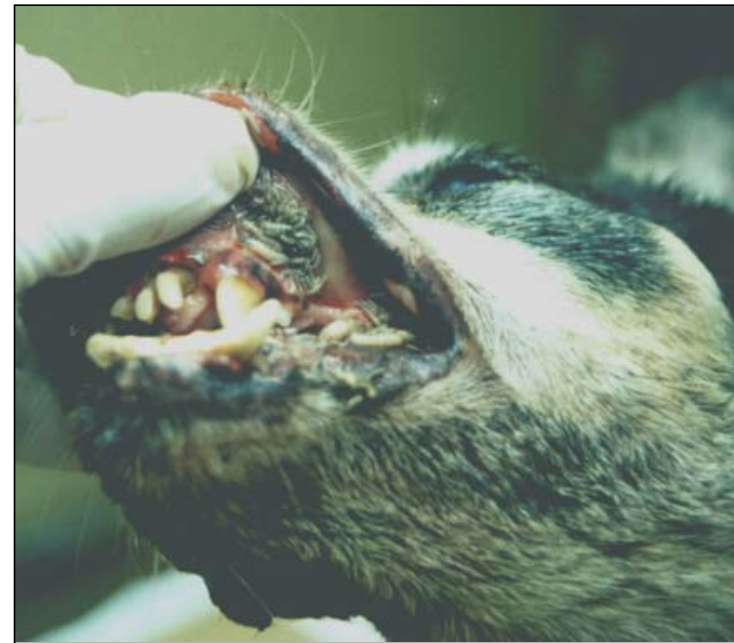

Figura 1b. Redução do número de larvas 6 horas após o uso de nitenpyram $(1,62 \mathrm{mg} / \mathrm{kg})$. [Foto: M.L.S Machado]

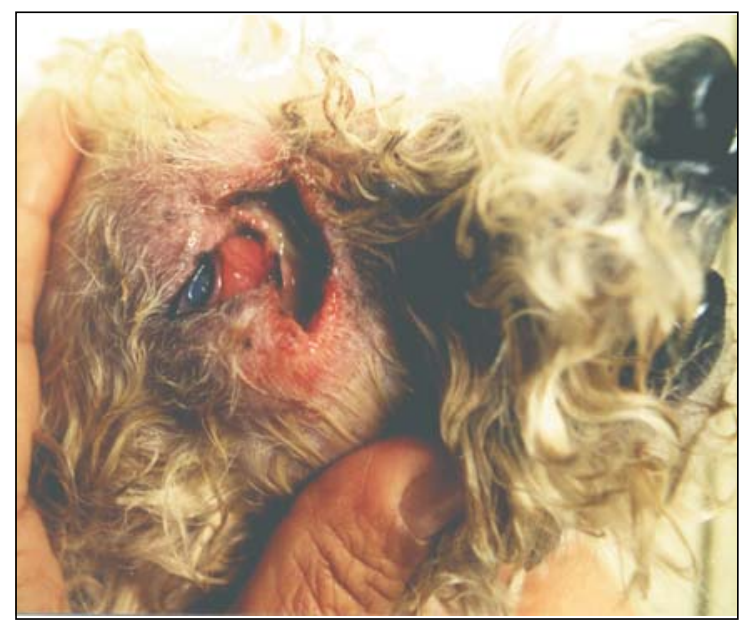

Figura 2b. Aspecto da lesão 24 horas após o uso de nitenpyram $(2,00 \mathrm{mg} / \mathrm{kg})$. Ausência total de larvas e melhora do quadro clínico. [Foto: M.L.S Machado]

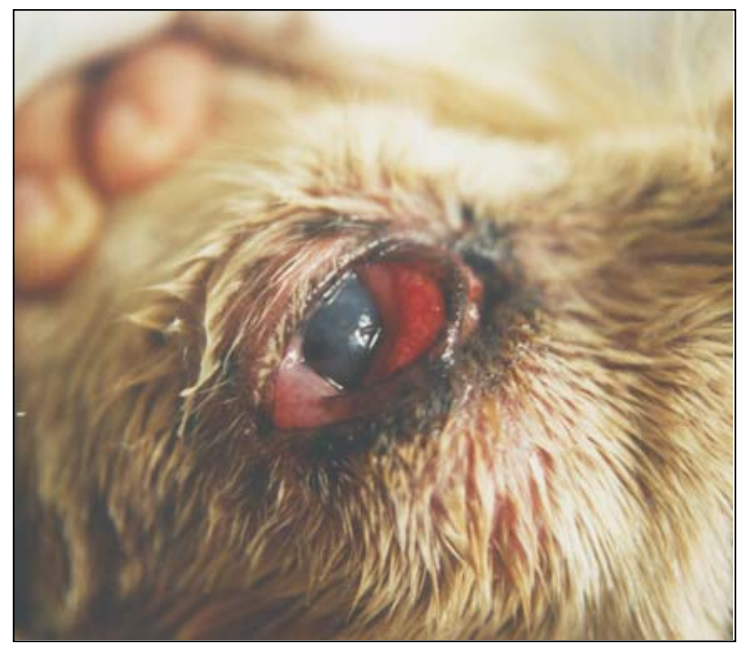

Figura 3b. Aspecto da lesão 24 horas após o uso de nitenpyram $(2.03 \mathrm{mg} / \mathrm{kg})$. [Foto: M.L.S Machado] 
um comprimido de $57 \mathrm{mg}(1,00 \mathrm{mg} / \mathrm{kg})$, e em 24 horas, ainda se observou a presença de larvas vivas. Foi administrada então, uma segunda dosificação de $57 \mathrm{mg}$, e em 24 horas, o resultado foi de $100 \%$ de larvas mortas.

As miíases, comuns em cães nos períodos de temperatura mais elevadas, além do desconforto podem causar seqüelas importantes. O seu tratamento normalmente requer anestesia e um demorado trabalho manual para retirada de larvas e debridamento de tecidos necrosados, com riscos à saúde animal e custos que podem ser muito elevados. A utilização de nitenpyram como medicação larvicida prévia à limpeza da ferida e à retirada de larvas, demonstrou-se muito eficaz nas dosagens indicadas pelo fabricante como pulicida. Em apenas um cão foram ainda observadas larvas vivas em 24 horas, e o mesmo pertencia ao grupo (2 cães) que recebeu doses de $1 \mathrm{mg} / \mathrm{kg}$ de nitenpyram. Tal observação pode indicar que a dosagem ideal de nitenpyram como larvicida de larvas de moscas $C$. hominivorax seja acima de 1 $\mathrm{mg} / \mathrm{kg}$, embora estudos com mais animais devam ser executados para confirmar tal hipótese.

Nos casos em que foram acompanhados no hospital, observou-se a morte de larvas num período em torno de 6 a 8 horas após administração da medicação [Figs. 1a e 1b]. A melhora do quadro clínico da ferida foi visível em 24 horas, em muitos casos, até em períodos menores, com redução do edema, contaminação e tamanho da ferida [Figs. 2a, $2 \mathrm{~b}, 3 \mathrm{a}, 3 \mathrm{~b}$ ]. A limpeza, realizada 24 horas após da administração da droga, foi muito facilitada, não sendo necessário, na maioria dos casos, anestesiar o animal e a resolução do processo foi acelerada.

Este experimento foi baseado nos quadros clínicos, não sendo realizada contagem, identificação sistemática das larvas, medição do tempo de ação do medicamento sobre a morte larval e nem acompanhamento hematológico ou bioquímico do animal em relação ao efeito da droga. Embora estudos mais pormenorizados devam ser realizados, nenhum animal apresentou quaisquer alterações clínicas, não evidenciando sinais de toxicidade da droga nas dosagens utilizadas.

Concluiu-se que o nitenpyram foi eficaz como larvicida para larvas de moscas Cochliomyia hominivorax em miíases caninas em 94,11\% dos animais estudados, utilizando-se as doses indicadas como pulicida pelo fabricante.

\section{NOTA INFORMATIVA}

${ }^{1}$ CAPSTAR: Novartis Saúde Animal Ltda. Av. Vicente Rao n. ${ }^{\circ}$ 90, C.E.P. 04706-000, São Paulo-SP.

\section{REFERÊNCIAS}

1 Acha P.N. \& Szyfres B. 1986. Zoonoses y enfermidades transmissibles comunes al hombre y a los animales. Washington: Organización Panamericana de la Salud, pp. 887-897.

2 Fortes E. 1987. Parasitologia Veterinária. Porto Alegre: Sulina, $453 \mathrm{p}$.

3 Nesbitt G. H. \& Ackerman L. J. 1998. Canine and feline dermatology. New Jersey : Veterinary Learning Systems, $498 \mathrm{p}$.

4 Sampaio A.P.S. \& Riviti E.A. 2001. Dermatologia 2.ed. São Paulo: Artes Médicas, $1156 \mathrm{p}$.

5 Novartis Animal Health INC. Available from: URL: http:// www.novartis. com.br/html/capstar/html. 